\title{
Current status of apps in smartphone of obstetrics \& gynecology, an observational study
}

\begin{abstract}
This observational study analyzes presently available apps in Smartphones in the field of Obstetrics \& Gynecology. Total of 137 apps were observed on IOS \& Android app stores. Largest number of apps were on Books, Conferences, Journals, Calculators, Obstetric wheels. 86\% apps were in English language. $75.91 \%$ apps were paid. RCOG guideline is one of the useful paid guideline app. The future beholds the development of ore locally relevant customized, cheap upto date apps.
\end{abstract}

Keywords: Apps, Smartphones, Android, iPhone, Gynecology, Obstetrics
Volume 7 Issue 5 - 2017

Girish Gupta, Abhinav Tomar, Kanchan

Thakur

Department of Pediatrics, SGRRIMHS, Dehradun, India

Correspondence: Girish Gupta, Department of Pediatrics, SGRRIMHS, Dehradun, Uttarakhand, India, Tel 918547876023 , Email dscnnf@gmail.com

Received: October 29, 2016 | Published: August 10, 2017

\section{Introduction}

About a decade back nobody could anticipate the revolution of Medical Apps on Smartphones and its all-round impact. ${ }^{1}$ Millions of apps have been developed, including large numbers in the field of medicine. However, one is not sure that how many apps are developed in the subject of Obstetrics \& Gynecology. Therefore, this observational study was designed to answer this research question of finding out apps in Obstetrics and Gynecology.

\section{Materials and methods}

Study design: Observational

Study population: IOS \& Android Operating Systems App stores, Apple store \& Google play respectively.

Study period: 30 days

Sample size: Determined by the number of apps available, All the apps retrieved with search words Obstetrics, Gynecology and Obstetrics \& Gynecology.

Ethical issues: None

Consent: Not required

A total of 137 apps were observed on the two apps stores \& their details are shown in Tables 1-4 with respect to their domain, language, payment profile \& guideline apps respectively. Most of the apps were common in Apple store \& Google play, however, google play had lesser number of apps.

Table I Apps Domain-wise distribution (Total Number of Apps: I37)

\begin{tabular}{ll}
\hline Domain of apps & Number of apps (\%) \\
\hline Books & $23(16.78)$ \\
Journals & $16(11.67)$ \\
Calculators & $10(7.29)$ \\
Osce tool & $1(0.72)$ \\
Guidelines & $4(2.91)$ \\
Practices & $8(5.83)$ \\
Obstetric wheels & $9(6.56)$ \\
Notes & $6(4.37)$ \\
Quiz & $4(2.91)$ \\
\hline
\end{tabular}

\begin{tabular}{ll}
\hline Domain of apps & Number of apps (\%) \\
\hline Board examination & $4(2.9 \mathrm{I})$ \\
Questions & $6(4.37)$ \\
US app & $\mathrm{I}(0.72)$ \\
Flash cards & $5(3.64)$ \\
Conferences & $20(14.59)$ \\
Patient tracking & $9(6.56)$ \\
Breast feeding & $2(1.45)$ \\
Baby care & $5(3.64)$ \\
Twins & $2(1.45)$ \\
Hypertension in pregnancy & $2(1.45)$ \\
\hline
\end{tabular}

Table 2 Apps Language-wise distribution

\begin{tabular}{ll}
\hline Language & Number of Apps (\%) \\
\hline English & II $(86.86)$ \\
Non-English & $18(13.14)$ \\
\hline
\end{tabular}

Table 3 Apps payment-wise distribution

\begin{tabular}{ll}
\hline Payment & Number of Apps (\%) \\
\hline Paid Apps & $104(75.91)$ \\
Free Apps & $33(24.09)$ \\
\hline
\end{tabular}

Table 4 Guideline Apps

\begin{tabular}{|c|c|c|}
\hline Name & Organization/ Developer & Paid/ Free \\
\hline RCOG guidelines & $\begin{array}{l}\text { Royal college of obstetricians \& } \\
\text { gynecologist }\end{array}$ & Paid \\
\hline Irish obs \& gynae guidelines & Michelle berkery & Free \\
\hline RANZCOG guidance app & $\begin{array}{l}\text { Royal australian \& } \\
\text { new zealand college of } \\
\text { obstetrician \& } \\
\text { gynaecologist }\end{array}$ & Free \\
\hline EFM guide & Joshua Steinberg & Free \\
\hline
\end{tabular}

\section{Results and Discussion}

Total observed apps were analyzed. Maximum number of apps were developed for the books, Conferences, Journals, Calculators, Obstetric wheels \& Patient tracking, while rest other domains were less represented. 86\% apps were in English language. 75.91\% apps were paid, one such highest costing app was Obstetrics: Normal \& Problem Pregnancies by Usatine Media LLC coasted Indian Rs 11900/-. There were four apps on guidelines, the RCOG guideline app 
was paid while other three were free apps. In the past points have been made about contraception, use of social media \& apps on Pregnancy, ${ }^{2-5}$ but present study revealed much wider applications of the apps in the field of Obstetrics \& Gynecology. Limitation of the study is the fact that it has not looked at all the operating system app stores \& hence has info on the two most utilized app stores.

\section{Conclusion}

This study clearly reflects present status of widespread utilization of apps in smartphones in the field of Obstetrics \& Gynecology and it is in consonance with contemporary medical science. It also makes one think that almost all areas of the specialty may be addressed by apps in more beneficiary centered manner, by making apps in local languages, at a cheaper price while getting more customized \& relevant.

\section{Conflicts of Interest}

None.

\section{Acknowledgements}

None.

\section{References}

1. Gupta G. Are Medical Apps the future of medicine? MJAFI. 2013;69(2):105-106.

2. O'Donnell BE, Lewkowitz AK, Vargas JE, et al. Examining pregnancyspecific smartphone applications: what are patients being told? $J$ Perinatol. 2016;36(10):802-807.

3. Lewkowitz AK, O’Donnell BE, Nakagawa S, et al. Social media messaging in pregnancy: comparing content of Text4baby to content of free smart phone applications of pregnancy. J Matern Fetal Neonatal Med. 2016;29(5):745-751.

4. Gal N, Zite NB, Wallace LS. Evaluation of smartphone oral contraceptive reminder applications. Res Social Adm Pharm. 2015;11(4):584-587.

5. Tripp N, Hainey K, Liu A, et al. An emerging model of maternity care: smartphone, midwife, doctor? Women Birth. 2014;27(1):64-67. 